\title{
A Theory of Literary Structuralism (in Henry James)
}

\author{
Ali Taghizadeh \\ English Department, Faculty of Arts, Razi University, Kermanshah, Iran
}

\begin{abstract}
Structuralism provides innovative grounds for the analysis of prose literature. The role of the fiction reader, story in the service of language, and story no longer for representing the concrete reality but for manufacturing new, relational, and pluralistic realities in language spaces are some of the outcomes of literary structuralism. The present article intends to discuss the application of Henry James's theories of the novel for providing a grammar of narrative. For doing this, it also attempts to show that James's theories of novel testify to the literary structuralisms of Claude Levi_Struass, Roland Barthes, Tzvetan Todorov, and Jonathan Culler. The role of language in James, his innovative narrative modes like the use of "scenic method" and "unreliable narrator," and the highlighted role of the reader in his last style which renders it a space of critical interpretation by the professional elite make his fiction structurally analyzable. In addition, these structuremaking features bear witness to what Barthes suggests "structural activity" of fiction should be based on. Some of these Barthesian formulas are: regarding the "text" as an open-ended site of signification which should consequently be handled differently from the "work," transferring the task of producing meaning from the author to the reader, and considering characters not as psychological entities but as "participants" in the formation of textual discourse. James's theories also testify to Todorov's theory of "absolute and absent cause" which he finds in the fiction of James and the outcome of which is the production of new frames of intelligibility. In addition, they give evidence to Culler's formula as to the production of meaning in novels, because reading James structurally is strategic for creating new realities in the space of language.
\end{abstract}

Index Terms — language, narrative, structuralism, James, Levi-Strauss, Barthes, Todorov

\section{INTRODUCTION}

The present article intends to provide a discussion of literary structuralism in the light of Henry James's theory of the novel. In a broad sense, "structuralism" includes the post-structural studies of fiction also (versions of deconstructive studies in narrative, New-Historical studies, cultural studies, film studies, etc.). But in the present article it stands for the linguistic study of the fiction of James on the basis mainly of the $20^{\text {th }}$-century narratologies including those of LeviStrauss, Barthes, Todorov, and Culler.

Standing in the midway between the English traditionally realistic fiction of the Victorian times and the modern unrealistic novel which is mainly psychological, the fiction of James puts more emphasis on language, point of view, characterization, and discourse. If the nineteenth-century English novel was realistically mimetic, which we read mainly for becoming better citizens, the present article reckons that the modern novel uses the sources of language to create structures where the sign plays freely and the reader finds occasion for practical criticism and interactive interpretation. Reading James structurally, we learn how to think about what we read, to interpret our readings, and to re-write them in our own perspectives.

Due to the existence of the following features in James's fiction, it can be meaningfully approached structurally. The first is that his real preoccupation as a novelist is not telling but is showing. This means that he is more interested in the how of storytelling - language, point of view, style - than in the what of it — events, narrative progression, and details of what happens. In addition, James's novels do not have a point either social or whatever. And his works are neither stories of characters and situations, nor are they sociological treatises in which we read about our duties to the other people. They are art, and James the artist is tirelessly interested in the formal properties of his work. If not for the complex knowledge about his international theme or the psychological enlightenment that he can give us, we can read James for the pleasure of his language and for his wit.

First of all, and very shortly, the roots of structuralism from the classical times to the rise of New Criticism will be discussed under "early structuralism." After that, it will be argued that the twentieth-century linguistics paved the way for different models of structural narrative studies. For doing this, narratological models of Levi-Strauss, Todorov, Barthes, and Culler will be described shortly. In these models, literature is often defined as a pure system of narrative language which structuralism claims can demystify. Then, it will be attempted to show how the theories of James testify to these models of narrative analysis.

\section{DisCUSSION}

A. Early Structuralism 
The works of Saussure and Russian formalists of the early twentieth century grounded the structuralist thought in its modern application. From the eye of the formalists, words in poetry did not function as signifiers only, for they were signifieds also. Formalists defined literature as a functional system, as a set of devices whose value was determined by other devices which were played off against them (those of other genres, past styles, etc.). For these avant-grade structuralists, a literary work presupposed other works, genres, styles, and structures of meaning which go beyond the work itself. And they regarded literature a kind of langue of which each specific work was an instance of parole. The French structuralists of the 1960s and 1970s carried these linguistic analogies further.

But if "structuralism" can be used for a description of "structures" and their functioning also, it can perhaps be traced back to the time of Plato and Aristotle. For Plato, the quality of poetic imitation rendered it a servile and untruthful discourse both in content and structure which consequently deserved to be exiled from his commonwealth. Aristotelian "structuralism," however, lies in his emphasis on the logical and ethical form of poetry. As to the former, he believed a poem should have a beginning, a middle, and an ending which are logically interrelated to each other, so that the result be an organic whole. About the ethical form, the Greek rhetorician proposed that the tragic hero should be a man whose downfall is not the result of his vice or depravity but the outcome of his error or frailty. In this sense, Horace too can be considered a structuralist, for he suggested the application of "the sugar-coated-pill theory of poetry“ (Hall, 1964, p. 15) for composing and teaching literature. For Longinus, the form of poetry was not very important, and sublimity was only the echo of a great soul. Yet, when he included "notable language" and "the proper construction of figures" (Hall, 1964, p 19) in his five fountains of poetical eloquence, he was, I think, structurally analyzing it.

The structuralism of the Renaissance literature rooted perhaps in the organization of a society which was well classconscious, for it was, among other things, the tripartite dramatic poetry in which the English hierarchical society was dramatized, a society where tragedy was for the highest class, comedy for the middle classes, and farce for the lowest ones. And decorum, which was badly needed for literature, meant appropriateness of each genre to the class of society which it mirrored.

The emphasis the poet-critic Alexander Pope put on "Nature methodized" (Abrams, 1987, p. 1092), the dialogue the poet laureate John Dryden put in the mouth of his men in "An Essay of Dramatic Poesy" (1668) where Neander "speaking in the climactic position, defends the native tradition and the greatness of Shakespeare, Fletcher, and Jonson" (Abrams, 1987, p. 886), and the significance Dr. Samuel Johnson ascribed to the unity of action in Shakespearean drama signify the structuralist views in the literature of Neo-classical era.

The Romantic poet-critics rose against the Neo-classical poetic "rules" and "decorum," for they believed they would make the poems artificial. However, if one realizes the four salient elements which were at work in a poetic creation (poetry as the utterance of emotion, poetic spontaneity and freedom, the glorification of the commonplace in poetry, and poetry imbruing landscape with human life) of the Romantic period, one admits of structuralist inclinations in the literature of that period too.

When the turn comes to the Victorian times, to the time of Hippolyte Taine (1928-1983) for example, the seeds of literary structuralism are already germinated. Taine approached literature perhaps as scientifically as the method of a biologist approaching his specimen could be scientific. However, the poet-critic T. S. Eliot was no less scientific in his approach to literature than Taine and no less disinterested. He claimed that poetry changes tradition but the mind of the poet remains unchanged to tradition. To make this idea of poet's depersonalization clear enough, Eliot offers an analogy. The mind of poet is like a piece of platinum when introduced into a chamber containing the two gases of sulphur and carbon dioxide. Continuing his analogy, he says, "The two gases then form sulphurous acid, but the platinum itself remains unchanged. The mind of the poet is the platinum. The emotions and feelings are the gases" (Hall, 1964, p. 168).

In this way, "early structuralism" in the present article should be considered as different from 20th-century structuralism. By the first, it is meant the sum total of what would make the external form and organization of a literary work, as well as the interests and curiosities of the teachers and students of literature. In this sense, structure was perhaps mainly an external aspect of poetry rather than an internal feature of it. The questions about the genre or type of a certain poem, about its metrical patterns, and about its rhyme scheme were handled for structure.

Along with this trend, form and structure in a work of prose fiction were considered as the total effect of its setting, action, plot, characterization, etc. This kind of structure was closely connected to the external form of a work of verbal art, which would be regarded not as dynamic and innovative but as static and mechanical. It was, among other things, the ground on which a literary scholar would stand to dissect the work for theorizing about it, and a threshold through which the student of literature should pass to look at the work via its numerous windows.

But only after Jean Piaget (1896-1980) had defined "structure" as the observation of any arrangement of entities which embodies the ideas of wholeness, transformation, and self-regulation, the term got its $20^{\text {th }}$-century application. Structure as such does not appeal to what is beyond itself but appeals only to what is interior to it. In a language space, wholeness guarantees internal coherence, transformation promises the dynamism of a system which permanently renews itself, and self-regulation secures the validation of its transformational procedures.

\section{B. 20th-century Linguistics vs. 19th-century Philology}

The nineteenth-century philology was symbolic. Each word was received as the symbol of an external object, while between the object and its symbol there was a one-to-one correspondence. Philology was diachronic also, i.e., it used to focus on language changes over long spans of time. The philologists paid more attention to the comparative studies of 
languages than they paid to the meaning of languages. And their researches seldom exceeded the etymology, grammar, and vocabulary of certain languages.

But the 20th-century linguistics is synchronic, ahistorical. Instead of focusing on etymological, lexical, and grammatical developments of certain languages through long time periods, it focuses on "studying a language at one particular time in its evolution and ... how the language functions" (Bressler, 1993, 60). A sign here is like a coin with the two sides of signifier and signified. The uttered sound, which the written mark introduces, is the signifier, while its concept (meaning) is the signified. Between the signifier and the signified there is no natural link, but there is a link which is only conventional and arbitrary. In the objective world, a word does not represent a referent but a concept in our mind.

Saussure also isolated langue from parole. "The former is," Culler says, "a system, an institution, a set of interpersonal rules and norms, while the latter comprises the actual manifestations of the system in speech and writing" (Culler, 2002, p. 9). Langue is the structure or system of language which is in the mind of the people and in which all members of a language community share. But parole is the actual speech utterances of an individual language user. A member of a language community can generate countless examples of utterances, but all of these utterances are governed by the system of that language, by its langue.

The relation between the sign and its referent is neither given nor innate, but is arbitrary, relational, and conventional. This by-the-way correspondence between language and reality makes the structural linguist curious about the source of meaning in language, about the process of signification. Meaning is differential, not the result of a one-to-one correspondence between the word and its referent, but is the result of sign differences. Therefore, the structuralist language scholar should study, not the isolated entities of a language, but the whole interrelationships among these entities.

Saussure believed that in language and other communication systems like fashion, sport, and friendship meaning is generated through a system of signs. Borrowing their linguistic vocabulary and their theory and methods from Saussure, and from Charles Sanders Pierce to a lesser degree, structuralists believe that codes, signs, and rules govern all human social and cultural practices. In this way, it can be claimed that structuralists find meaning in the relationships among the various components of a system of communication.

\section{New Criticism vs. 20th-century Structuralism}

The school of New Criticism stands in the midway between the conventional approaches of literary criticism and the 20th-century structuralism, and it has many things in common with structuralism. For example, what Barthes calls the "death of the author," implies the lack of authorial control over the text in the act of reading which leads to the (complete) freedom of the reader which is, in turn, in concert with the autonomy of the literary text in New Criticism.

However, New Criticism seems divergent from structuralism in some other points. The former consider individual literary texts "as 'works', or as artfully constructed icons, or as distinct and separate objects" (Selden, 1989, p. 29). They take a work of fiction as an autonomous object, and the act of reading as ontological, because the reader focuses mainly on the internal elements of the object like its language, diction, paradox, irony, ambiguity, tension, and rhyme scheme. However, the sum total of these features is the structure of the work about which the critic is then able to pass judgment. Each time he reads a text, he can produce a meaning which is different from that which the author had in mind. New Critics assert that in a reading process neither the author is central nor the reader, but it is "the text and the text alone" (Bressler, 1993, 33) that is of prime importance.

But in the $20^{\text {th }}$-century structuralism the study of languge is not historical but is ahistorical, for Saussure used to study language not for its developments through time but for its internal structure in a given time. Language is considered as a social system that is coherent and orderly, and that can be understood as a whole. In addition, meaning is no inherent or natural feature of language, and it is not an absolute entity. On the contrary, it is, in the never-ending sequence of signifiers, the result of the juxtaposition of the signifiers. This means that meaning, which is the outcome of sign differences, is structural, relational, and subject to change.

Before going any further in the discussion of structuralism, let's provide a short profile of the broad school of Reader-Response criticism of which structuralism is only a subtype. Although Reader-Response criticism can be traced back to the $2^{\text {nd }}$ and $3^{\text {rd }}$ decades of the 20-century, it was in the 1970s that Louis Rosenblatt formally established it. The proponents of this school put emphasis on "the reader's reception of a text; ... on the altering responses, interpretive and evaluative, of the general reading public over the course of time" (Abrams, p.272). Thus, it seems rather polar with New Criticism. However, Reader-Response critics do not deny the role of the text in interpretive reading. And the meaning is, they claim, the result of a transactional experience that takes place between the text and the reader. The advocates of this school are usually divided into three groups of: reader-oriented critics, reader-plus-text critics, and text-oriented critics. Structuralism is the act of reader-plus-text critics, the criticism of those who believe in the act of interpretation the text and the reader are equally important.

\section{Structuralism in Modern Literature}

\section{Intertextuality}

When applied to literature, structuralism becomes radical and increasingly irreducible. The 20th-century literary criticism rejects the view that regards literature as a means of communication between the author and the reader. It is in 
sharp opposition with the 19th-century theories of language that were mimetic and expressive. A proper study of literature is not, structuralists say, a close reading on the separated literary texts, but is an inquiry of the conditions that are influential on the act of interpretation. So, structuralists often investigate the system whereby individual texts are related to each other, because they believe that they are only expressing agents of a superior social and cultural system. From their viewpoint, the primary task of the critic is to study the "grammar" of literature, the system of rules that govern literary interpretation. Thus, they often search for the common understructures of literary productions of a certain author or even a whole period.

This indicates the "intertextuality" of meaning in structuralism, the space in which while reading a text, one would like to locate as many connections (references) as possible to as many other texts as possible. The outcome of intertextuality can be the creation of a universal text, or as we read in A Glossary of Contemporary Literary Theory, an "intertext (that is, the text within which other texts reside or echo their PRESENCE" (Hawthorn, 1992, p. 126). Intertextuality is a dimension of the text which comes into existence when individual texts enter the interior of other texts, an all-encompassing text of which every other text is only a sub-text.

\section{Literature and Language}

Structuralism brings literature together with language. In A Glossary of Literary Terms we read, "As applied in literary studies, structuralist criticism views literature as a second-order system that uses the first-order structural system of language as its medium, and is itself to be analyzed primarily on the model of linguistic theory" (Abrams, 1993, p. 280). In this position, structuralism is a linguistic study of literature, a search for the langue of it.

For a structuralist analysis of literature, it is strategic to investigate all literary productions of a certain author or even a whole period. The primary task of such an analyst is to study the grammar of literature, that is, the rules that govern the production and interpretation of fiction as a verbal structure. An inference of this is perhaps that literature and language are similarly structured: the first is a self-enclosed system of rules that is composed of language, while the second needs no outside referent but its own rule-governed and socially constrained system.

A further feature of structuralism is its capacity to demystify literature scientifically. It denies literature of any mystical power which has heretofore been bestowed upon it. Structuralists claim that they can delve deep into the grammars of language and narrative, and unravel the secrets of literary texts. Therefore, the text is no longer a unique and autonomous object, and the author's intention is not the same as its overall meaning, for meaning is determined by the system that governs the author. All texts refer to other texts, which is another indication of intertextuality of meaning.

\section{A Methodology of Literary Structuralism}

\section{Levi-Strauss: Structural Study of Myth}

In structuralism the base of interpretation is the common interpretive language of a certain generation that is made of signs and symbols and in which the members of that language community share. Depending on their backgrounds and viewpoints, two certain readers may react differently to a same literary text. Although the revised text produced by a structuralist analyst is not as genuine as that of the original writer, in the examination of the new culture it is the analyst who holds the primary position. What the writer has created as concept, the structuralist critic deals with as sign, and he reads the text as a cultural production that is manufactured according to various perceptions, routines, and traditions of that culture.

Such a critic never ignores the meaning but treats it as mediated by the signs. Structuralism is an intrinsic reading that is free from subjectivity. And the structuralist critic searches in the text for order and coherence and meaning, while his goal is to provide an objective criticism of the text. So, he transverses barriers of time and interest, and tries not to be trapped by his prejudices and partialities. Yet, the text leads him to topics (or the culturally-constructed sites of meaning) that underlay the ways we think and talk about the things of our culture.

After Saussure, structuralism has become as diversified in methodology almost as the practitioners of it. In the first place, there is the mythological approach of the French anthropologist Claude Levi-Srauss who wanted to discover the langue of the myth. In his mythology, there is a "shift of emphasis from myth as a sort of PLOT to myth as a sort of thinking with close resemblance to (...) IDEOLOGY" (Hawthorn, 1992, p. 159). For Levi-Strauss, myth is structured like language, and every myth is therefore an example of parole. For discovering the language of the myth, he used to read countless myths and to identify the recurrent themes that run through all of them which he named mythemes. As the building block of a myth, a mytheme takes the same role in it as a phoneme takes in language. Such a nodal object finds meaning only within a mythic structure. This means that the meaning of a myth depends both on the structure of the myth and the distribution of mythemes within the story. Therefore, the meaning of the myth originates from this structural pattern which we unconsciously master.

\section{Todorov: Grammar of Narrative}

There are also the narratologies of Vladimir Propp and Tzvetan Todorov. Like Saussure and Levi-Strauss, these narratologists illustrate how the meaning of a story develops from its overall structure (its langue) rather than from the isolated themes of individual stories. The Russian theorist investigated the fairy tales of his country and described their langue.

But Todorov attempted to describe the grammar of the fiction of Henry James's last style. In Poetics of Prose and "Structural Analysis of Narrative," he "seeks to develop a 'poetics' or a theoretical study of literary techniques and 
categories" (Leitch, 2001, p. 2097). He focuses on the universality of grammar and argues that the grammar of language reflects the grammar of narrative. The grammatical clause is the basic interpretive unit of the sentence. It can be analyzed into some categories to describe the division of narrative into meaningful unites of structure. He discusses the narrative structure in two levels of speech and discourse. On the level of speech, words signify not only the entities but also their characteristics. For example, the word "book" stands for an object as well as for the features of that object. Proper nouns and pronouns are chiefly denominative, while common nouns and verbs are descriptive. Todorov keeps denominations solely within the subject and descriptions within the predicate. He also considers several classes for the predicate. The minimal complete plot consists of the movement of the narrative from a state of equilibrium to another one. An ideal plot begins with a stable situation which is disturbed by a force the result of which is a state of disequilibrium. But when by the action of a force directed in the opposite way the equilibrium is re-established, the plot attains perfection. The second equilibrium is similar to, but never identical with, the first.

To describe the level of discourse, Todorov analyzed some stories of Decameron. He distinguished three types of narrative propositions that corresponded to the logical relations of exclusion (either-or), disjunction (and-or), and conjunction (and-and). The first is alternative. The second is optional, and the third is obligatory. The relations between propositions can be of three types. When they are temporal, the events follow one another in the text because they follow one another in the imaginary world of the book. When they are logical, narratives are habitually based on implications and presuppositions. And when they are spatial, narrative prepositions are juxtaposed because of a certain resemblance between them. In the novellas of Decameron, Todorov discerned two types of story. The first type, where a complete trajectory (equilibrium--disequilibrium--equilibrium) was available, was a "punishment-evaded" story. But the second type, where only the second part of the narrative is present, is a "conversion" story. Here the narrative starts with a disequilibrium to arrive at a final equilibrium.

An average reader studies a fiction above all for plot as the sum total of its incidents. But interested in the theoretical problems of structuralism, Todorov discussed plot both as an abstract concept and an issue of the structural approach to narrative, and he suggests useful categories for a close scientific scrutinizing of it. Plot consists of action, character, and recognition. The Franco-Bulgarian narratologist has provided a schematic formulation for a number of Boccacio's plots: "X violates a law $\rightarrow \mathrm{Y}$ must punish $\mathrm{X} \rightarrow \mathrm{X}$ tries to avoid being punished $\rightarrow \mathrm{Y}$ violates a law $\rightarrow \mathrm{Y}$ believes that $\mathrm{X}$ is not violating the law $\rightarrow$ Y does not punish $X^{\prime \prime}$ (Vincent, 2001, p. 2013).

\section{Barthes: Structural Analysis of Narrative}

The work of Barthes is somehow like that of Todorov. But the writer of $S / Z$ concentrated on popular forms of literature. In "An Introduction to the Structural Analysis of Narrative" he has discussed the structure of narrative perhaps better than elsewhere. Narrative is a pure system, and a discourse is a "large 'sentence' (...) in the same way that a sentence, allowing for certain specifications, is a small 'discourse'" (Barthes and Duisit, 1975, p. 240), for there is nothing in the latter that is not matched in the former. He analyzes the structure of discourse in three levels of functions, actions, and narration. In a structural study of narrative, the first step is to break it into smallest meaningful segments which he calls "functions." Thus, a narrative function is a content unit.

On the level of actions, he examined mainly the narrative agents. In Aristotelian poetics, "the notion of character is secondary, entirely subordinated to the notion of plot" (Barthes and Duisit, 1975, p. 256). But with the emergence of philosophical and literary humanisms in the European Renaissance, character took on psychological consistency and became a fully constituted being, a particular individual. However, "Anxious not to define character in terms of psychological essences, structural analysis has so far attempted, through various hypotheses, to define the character as a 'participant' rather than as a 'being'" (Culler, 2002, p. 272). As a participant, it is an agent to which a series of actions belongs which give meaning to its existence through interaction with the other agents in the formation of narrativity. An aftermath of this new look is that narrative power is prevented from blocking in a certain segment or character, but via a narrative decentralization, the power of discursivity is given out to all agents who share in the formation of the narrative, for "each character, even a secondary one, is the hero of his own sequence (Barthes and Duisit, 1975, p. 257).

On the level of narration, there is a giver of narrative (narrator) and there is a recipient of narrative (listener). In a linguistic communication, the existence of "I" can be granted by "you" while the existence of "you" can be granted by "I". Similarly, if there is no giver or no receiver of narrative, no narrative can exist. However, Barthes questions about the real "giver" of narrative. Three answers have been given to this question. The first recognizes the author of a narrative as its giver, the second considers an omniscient impersonal consciousness for its deliverer, and the third takes a character-transmitter in the narrative as its narrator. But all these conceptions are inadequate for Barthes, because "at least from our viewpoint, both narrator and characters are essentially paper beings" (Barthes and Duisit, 1975, 261). He notifies us that the living composer of a narrative should not be mistaken with its narrator.

\section{Culler: Analysis of Interpretation}

There is also the reader-based narrative studies of Jonathan Culler in the mid-1970s with which the American structuralism began. Culler believed that the abstract linguistic models which narratologists have so far used tend to focus on parole, and proposed that instead of it we should work on the analysis of interpretation. He did not pay much attention to the actual content of the text but emphasized its form and structure. Designing a theory of reading, he questioned about the internalized systems of literary competence that the readers use to interpret a literary text. Culler was more deeply interested, not in the texts themselves, but in the rule-governed system that underlies the texts. He 
suggested that a structuralist analyst should focus his attention more closely on the langue of narrative, and should spend time to analyze the interpretation of individual stories and poems. Therefore, reading a literary text structurally, we should work for the establishment of the system that undergirds a reading process. How texts mean, not what texts mean, should be our chief interest.

\section{Structuralism in James's Theory of the Novel}

"The Art of Fiction"

James's critical productions can be divided into two categories of reviews and critical essays. In "The Science of Criticism" (1891), he makes some differences between the two: review is more commercial, dogmatic, and conventional; while criticism is truth-oriented and is more speculative and intellectual. The former is fundamentally evaluative, but the latter is more analytical and theoretical. James's criticism is associated with the literary or academic world, and is directed toward a disinterested enrichment of culture. James the reviewer had only to pass judgments on individual literary works, but James the essay writer had occasion, through critical analysis, to attune his newly expanded readership to the seriousness of prose fiction as an art form and to its technical presentation strategies.

However, it is "The Art of Fiction" (1884) which is James's critical manifest of the theory of modern novel. About 20 years before the publication of this article, he had warned the literary scholars of the vulgarity of Victorian fiction. But this article is the document of his successful attempt to fill in the gap, for if it does not provide a poetics of the Victorian novel, it surely produces the backgrounds of the poetics of the modern fiction.

Therefore, this article indicates a turning point in James's career. It shows him reflecting on the art of novel, and marks his true entry in the domain of literary criticism as a major writer. In addition, James's moral attitudes are more complex and analytical in this article than elsewhere. And it shows him attempting more genuinely to absorb the attention of an intellectual audience.

\section{James's Prefaces}

On the one hand, James the critic often insisted that his fiction should be understood properly. On the other hand, the huge variety of his critical analysis indicates that he was aware a lacuna existed in his fiction. But although he attempted to supervise his readers how to fill in the gap, his prefaces (to his tales and novels) do not elucidate the difficult allusions in his work. They are also not in the nature of a philosophical debate or critique of the contemporary English novel. Instead, they want to satiate his desire to design a formula for the appreciation of his fiction. Explanatory and vindicatory as they are, they want to provide a justification of his fiction, and to offer a rationale for his theory of the novel. If this is right, it can be suggested that his prefaces also show him a pathfinder in the theory of the modern novel.

James the critic defended the same principles which he practiced in his fiction. He focused his mind on the relations between art and artist, art and life, art and ideals, and art and morals. He most applauded the literature that was tightly composed, that showed the author in the achievement of difficult effects through knowledge and mastery, and that, consequently, required the close attention of the reader.

However, he could not conceive of a novel without form, and his conviction in the form of the novel as integral to its content, is, I assume, a salient dimension of his structuralism. He also conceived of a novel as a structural manifestation of a selective and discriminating consciousness. No tailor recommends using a thread without a needle and using a needle without a thread. Likewise, in a work of fiction the subject and the treatment, or the story and the novel, cannot be divided from one another.

In "The Art of Fiction" James does not separate the moral sense of a literary text from the taste of the author, and this interfusion of taste and morality is, I suppose, another indication of James's structuralism. In support of this moralistic relativism in modern fiction, Martin Kreiswerth asserts "morality in the novel stems not from consciously implanted ideas but from the whole cast of the artist's informing consciousness" (1995, p. 423). Therefore, in the eye of James morality is no longer a didactic question but is an aesthetic question, a possibility for the production of new realities in the consciousness as the agent of discursivity. To achieve higher degrees of aesthetic morality, James creates a world of illusion with which he entangles his readers not only in their senses, but also in their hearts and brains.

Before the publication of "The Art of Fiction," subjects like fact and fiction, realism and romance, and art and science dominated the debates of novel. The novel was conceived as an untruthful form of art which was illegitimate and in severe disrepute. In such a situation, in order to escape conviction and find readership, the novel had to pretend that it is not a serious discourse but is a jocular speech which has nothing to claim. However, in this treatise James paved the road for fiction not only to escape from the humiliating shame of jocularity but also to be considered as a legitimate form of art which is faithful to the reality of life. Thus, the pretending humiliation of the novel provided it with a large space of freedom where the novelist could open his mind to all kinds of impressions. And this all-encompassing impressionistic freedom of the novelist in turn brought the whole reality of life into his accession which he could represent in an artistic form. The novelist would structure his work so artistically that its attentive reader could dramatize in it a one-to-one correspondence between the things of life and the taste of the novelist. Thanks to James's manifest, story writers started to focus their minds more emphatically on the relations between content and form, subject matter and technique, or life and art. This is to mean that following "The Art of Fiction," critics of the novel started to accent the craft, technique, or structure of it as heavily as the content of it, and its relation to reality. In this way, the idea of good and/or bad novels was no longer a matter of morality but was a matter of taste (of the writer and/or reader). It was artistry of the work, but not its morality, which the critic would hereafter regard as the 
measurement of it badness and goodness; and its artistry was, in its turn, the distinction of its interest and its distribution among the readers.

Thus, although James may have heard nothing about "structuralism" as a formal approach to literature, he can be said to have paved the way to it. This stated, the secret of James's structuralism lies in a number of elements like: his emphasis on the absolute freedom of the novelist in the reception of different kinds of impressions for the production of his work, his insistence on the freedom of the story from morality in order to make it a subject of the taste of the artist, and consequently, to change it into a matter of aestheticism, the highlighted role he granted to the reader in the reproduction of the story via critical interpretation, his emphasis on language in the composition of the work through which the consciousness of the reader gets transcended, and his insistence on the point of view from which the story is narrated. These dimensions have changed the novel from the expression of a pre-planned and limited sequence of meanings to a realm of discursivity where the relations of art and life are problematized and the critical reader reproduces reality in the space of story when it is in the service of language.

\section{CONCLUSION}

In Saussurian structural linguistics, language is studied not diachronically but synchronically. The word is no longer a symbol with a given and one-to-one connection with its referent but is a two-layer sign of which the signifier is the vocal utterance (or the written mark) and the signified is the meaning of it. Language as a system of signs, is also a social contract where signification is not absolute or pre-given but is arbitrary, conventional, and the result of sign differences.

In later decades of the $20^{\text {th }}$ century, many thinkers continued the researches of Saussure and provided their own models of narrative studies. Levi-Strauss built on his findings to introduce a structural system of anthropology an aspect of which is the study of myths. From the perspective of Levi-Strauss, a myth is a body of narrative materials which comprises a particular aspect of a given culture. We realize that the myth is structured like the language, that both of them are bilinear systems, and that therefore we should study them vertically as well as horizontally.

For Roland Barthes, the unit of study in linguistics is the sentence, but although discourse lies beyond linguistics, there is nothing in the discourse which is lacking in the sentence. Therefore, it is most reasonable to study the discourse in the same way we study the sentence. A narrative should be studied on the three levels of functions, actions, and narration. A function is a unit of meaning. An action should be no longer ascribed to characters as psychological entities but to actors which are the participating agents in the formation of the discourse as a relational structure. And narration is possible to take shape only in an in-between space, because the giver of narrative guarantees its receiver, while the receiver testifies to its giver.

Tzvetan Todorov argued that grammar is universal, and that the grammar of narrative is analogous with that of language. A narrative plot consists of a movement from a state of equilibrium to a state of disequilibrium and back to a state of equilibrium again. But although the first and last states of equilibrium are similar, they are not just the same. He also studied the later style of Henry James, and theorized that the constitutional discursive element in his fiction is a search by the reader for a cause which is perpetually "absolute and absent" (Todorov and Wienstien, 1973, p. 74). And Jonathan Culler's narrative studies are mainly reader-based. Instead of studying individual narratives, he sought in them for the rules that underlie the act of interpretation. In this way, he centered his investigations on the analysis of narrative interpretation, on how novels produce meaning.

Therefore, the fiction of James can be fruitfully approached structurally, because firstly, one can develop a thorough collection of structuralist narratologies from his own theories of novel, while his fiction is also the embodiment of his theories. And secondly, James's theories of novel testify to the $20^{\text {th }}$-century literary structuralisms some of which the present article has attempted to discus.

James writes mainly for the emergence of a transactional experience between the text and the reader through the establishment of an interpretive process without which reading is absurd and enlightenment is impossible. His last style is not for naïve reading but is for critical analysis by professional readers. He has a positive horror of generalization, and his fiction is, among other things, for the representation of the minutest details of life as well as for the reproduction of discursive realities in narrative spaces. James is content only with the facts, but the source of the Jamesian fact is the perception of the critical reader insofar as he participates in the revision of the narrative for the formation of new discourses. So, he never tells his reader what to think but only puts him in a narrative space where the outcome of his negotiation with the characters should be the emergence of new significations.

Therefore, the job of the structuralist reader of James is to understand how the structures work in his fiction, that is, how the elements of the story come together and render it into structures which he can discover. A technique for reading him structurally is to fill in the numerous gaps which he leaves in the text of each of his great novels and tales. But James's reader can fill in these gaps only when he actively participates in the act of reading. In addition, his stories can be analyzed not only as spaces of interpretation but also as occasions of self-realizing.

Reading James, we use dialogue not for unfolding idea but mainly for displaying humor, and we use the past perfect tense for retrospection, that is, for exploring the reminiscences of characters. Reading James, we use a story which is less episodic but more contemplative and psychological, and we discover the role of a confidant character who is "inevitably a woman - with whom the (generally male) observer or actor may discuss the situation, comparing notes 
and checking up theories" (Beach, 1954, p. 70). Reading James, we comprehend the formative function of verisimilitude, we realize the role of a careful process of selection and elimination, and we acknowledge the consistency of the effect for which an author may compose his stories.

In James we have to deal with an abstract diction and a complicated syntax, we have to deal with numerous parenthetical interruptions, and we realize the effect of a neutral tone of story-telling. In James we observe the application of the "scenic method" of narrative and the role of innovative points of view. We also learn how a great novelist can meaningfully sustain the suspense in his plot, i.e., how he doles out his information in bits and makes his reader anxious to get more knowledge each time. In James we attempt to discover the secret of many expletive and passive grammars, we note the lack of correlation between diction and syntax, and we learn the mentality of many subtle persons. In James we also note the absence of the author from the scene of interpretation and the presence there of a central character through whose mouth the author speaks, while we also note that through his absence the author exempts himself from passing judgment on the things and allows the reader to interpret the story.

\section{REFERENCES}

[1] Abrams, M. H. (1993). A Glossary of Literary Terms. $6^{\text {th }}$ ed., 1941. New York: Harcourt Brace College Publishers.

[2] Barthes, Roland. (1974). S/Z. trans. by Richard Miller, New York: Blackwell Publishing.

[3] arthes, Roland. (1994). The Semiotic Challenge. Berkeley: University of California Press.

[4] Barthes, Roland and Lionel Duisit. (1975). "An Introduction to the Structural Analysis of Narrative." New Literary History. Vol. 6, Issue 2. pp. 237-272.

[5] Beach, Joseph Warren. (1954). The Method of Henry James. Philadelphia: Albert Saifer.

[6] Bressler, Charles E. (1993). Literary Criticism: An Introduction to Theory and Practice. New Jersey: Prentice-Hall Inc.

[7] Brooks, Van Wyck. (1925). The Pilgrimage of Henry James. New York: E.P. Dutton Company.

[8] Budd, Louis J. and Edith, H. Cady. (1990). On Henry James: The Best From American Literature. Durham: Duke UP.

[9] Crook, Dorothy. (1962). The Ordeal of Consciousness in Henry James. Cambridge: Cambridge UP.

[10] Culler, Jonathan. (2002). Structural Poetics: Structuralism, Poetics, and the Study of Literature. London and New York: Routledge, (Original Work Published in 1975).

[11] Dryden, John. (1688). "An Essay of Dramatic Poesy." The Norton Anthology of English Literature: The Major Authors. General Editor: M. H. Abrams, New York \& London: Norton \& Company, 1987.

[12] Krieswirth, Martin. (1994). "James, Henry." The Johns Hopkins Guide to Literary Theory and Criticism. Michael Gredon and Martin Kreiswirth Eds. Baltimore: The Johns Hopkins UP. pp. 419- 423.

[13] Hall, Vernon. (1964). A Short History of Literary Criticism. London: The Merlin, Press Ltd. (Original Work Published in 1963).

[14] Hart, James D. Ed. (1995). The Oxford Companion to English Literature. $6^{\text {th }}$ ed. New York: Oxford UP. (Original Work Published in 1941).

[15] Hawthorn, Jeremy. (1992). A Glossary of Contemporary Literary Theory. London and New York: Edward Arnold.

[16] James, Henry. (1948). "The Art of Fiction” The Art of Fiction And Other Essays by Henry James. New York: Oxford UP.

[17] James, Henry. (1964). The Ambassadors. Intro. by R. P. Blackmur, New York: Dell Publishing Co. inc.

[18] James, Henry. (1983). The Golden Bowl. Intro. and notes by Virginia Llwellyn Smith. Oxford: The World's Classics.

[19] James, Henry. (1947). "The Figure in the Carpet” Selected Tales of Henry James. London: The Richards Press. pp. 177-217.

[20] McCarthy, Harold T. (1958). Henry James: The Creative Process. New York: Thomas Yoseloff.

[21] Pelham, Edgar. (1927). Henry James: Man and Author. Boston: Houghton Mifflin Company.

[22] Pope, Alexander. (1711). "An Essay on Criticism" The Norton Anthology of English Literature: The Major Authors. General Editor: M. H. Abrams, New York \& London: Norton \& Company, 1987.

[23] Selden, Raman. (1989). A Reader's Guide to Contemporary Literary Theory. New York: Harvester Wheatsheaf. (Original Work Publishid in 1985).

[24] Selden, Raman. (1989). Practicing Theory and Reading Literature: An Introduction. New York: Prentice Hall.

[25] Todorov, Tzvetan and Arnold Weinstein. (1973). "The Structural Analysis of Literature: The Tales of Henry James." Structuralism: An Introduction. Ed., David Robey. Oxford: Clarendon Press. pp. 73-103.

[26] Todorov, Tzvetan, (1977). The Poetics of Prose. Ithaca: Cornell UP. Leitch, Vincent B. Ed. (2001). "Structural Study of Narrative" by Tzvetan Todorov. New York and London: Norton \& Company. pp. 2097-2016.

Ali Taghizadeh is an assistant professor at the English Department of Razi University of Kermanshah, Iran, where he has taught English language and literature for 15 years. He has got a B. A. in English from Shiraz University and an M. A. in English from Tehran University. The title of his M. A. thesis is "The Archetypal Theme of Expiation in Six Major Novels of Thomas Hardy and William Faulkner: A Comparative Analysis." He has also got a Ph. D. in "American Studies" from John F. Kennedy Institute for North American Studies of Free University of Berlin, and the title of his doctoral dissertation is "Structuralism and Its Aftermath in the Fiction of Henry James." He is working on some research projects including a post-doctoral one which is a comparative study of the postmodern Iranian and American fiction as a space for cultural studies and which he is doing in Cologne University English Department. He is also working on a translation project (a translation into Persian of the English version of Derrida's Of Grammatology). The main research interests of Ali Taghizadeh are fiction, literary history, narrative theory, and American (cultural) studies. He has already translated a book by J. Hillis Miller into Persian, and has published some articles in his areas of interest. 